\title{
Australian Indigenous sensory knowledge systems in creative practices
}

\section{创意实践中的澳大利亚土著感官知识系统}

\author{
Liz Cameron \\ Deakin University, Australia
}

\begin{abstract}
The process of making is transmitting knowledge through an act of doing. Perceiving the body as a multisensory being pushes Australian Aboriginal artistic encounters that challenge other ways of thinking and doing. This article explores the nexus between Indigenous knowledge and creative practice as an embodied theoretical framework based on the human senses that may assist artists in deconstructing their current conventical thinking and broaden their interaction by deeply connecting with self and the environment. This article aims to highlight Indigenous practice-based methodologies that can inform the artist to practice research and teaching resources. Examining Indigenous creative knowledge systems can enable artists to experience not only an acquisition of content of Indigenous practices but develop a unique methodological Indigenous approach to how our senses offer a valuable contribution to the making experience.
\end{abstract}

Keywords: Indigenous methodology, creative making, human senses, imagination, intuition

\section{摘要}

制作的过程是通过做的行为来传递知识。把身体看作是一种多感官的存在，促使澳大利 亚原住民与艺术相遇，挑战了其它的思维和行为方式。本文探讨了土著知识和创造性实 践之间的联系，作为一个基于人类感官的具身化理论框架，可以帮助艺术家解构他们目 前的传统思维，并通过与自我和环境的深度联结增加人与自然的互动。本文旨在强调基 于土著实践的方法论，可以为艺术家提供实践研究和教学资源。对土著创造性知识系统 的研究可以使艺术家不仅通过体验收获土著实践的内容，而且发展出一种独特的土著知 识方法论，即我们的感官如何有益地促进了创作体验。

关键词: 土著方法论，创作，人类感官，想象力，直觉

\section{Introduction}

Much has been written about art-making but not concerning the body-mind connectivity that is key in driving Australian Indigenous creative practices. The omission of bodily awareness lies in the conception and function of art through a dominant Western lens that views creativity as a cognitive process derived from a combination of personal talents and training (Pascual-Leone et al., 2005); its excellence preserved in museums. Indigenous creative pedagogies are a systematic form of knowing that utilizes the scientific structures of multisensory knowledge to interact with spiritual space and 
cultural place. Indigenous methods of knowing focus on bodily sensory connections to transmit ideas and values inherent to culture, unlike Western notions that perceive art-making as a skill of esthetic appreciation.

Creative processes require not only knowledge known over time and practice but also a willingness not to be constrained by our existing knowledge. The act of being creative is in and of itself an act of making "new" the form or idea. Creativity is socially endorsing within the many paradigms that assume it has value-neoliberalism sees the creative endeavor as a process for making ingenious and moneyed systems; meanwhile, social justice and critical paradigms see it as a way to propose new ways of being and the disruption of the values and attitudes that are socially unjust. As artists and performers, we should challenge established knowledge of all forms so as to help free ourselves of the confines of existing knowledge and their paradigms or philosophical stance. This is the goal of this paper. I will show another way of knowing, and the epistemic point of view is deeply threaded in history but concurrently brings "new" knowledge to the world of art-making.

Using both implicit and explicit knowledge dimensions in the creative processes allows for the free flow of encounters, which are both analytical and subjective experiences. The act of "doing" is an experimental process that involves a tactic engagement. The power of these knowledge forms is central to our understanding. Still, it is the act of acting - "action" or the "doing"- through a multisensory tactic experience that lets us encounter the unknown and known knowledge. These various knowledge systems are known to us as implicit, explicit, and analytical, but always subjective. This subjectivity is the esthetic encounter, and it is through an internalized process of the esthetic that we can explore the relationship among creative practice, experience, imaginative space, and intuitive reasoning. In artistic processes, through any lens, there is always a concatenation of sequenced events - a restless search for exciting forms and meanings. These meanings are made known to us through affect and emotion and become awake (esthetic) in us through our senses. Elsewhere, the notion of how our knowledge has been put to sleep (anesthetized) could be explored, but in this paper, let us assume it is natural and the senses are known to us and warrant exploration.

By using our natural human senses, we can respond to certain stimuli on an automatic or preconscious level. The nature of the preconscious knowing is not easily understood but has been known to the world of Aboriginal people from time eternal. Preconscious knowledge is always associated with a part of the mind that is below the level of direct conscious awareness or as used here "knowing." The preconscious is the realm from which remembrances, recollections, and the deep gnosis along with emotions that may or may not been repressed can be recalled. Aboriginal and First Nations people have had a long history of deep knowing and have become known as the Indigenous ways of "doing" in the making of artwork. This making is grounded in the pedagogics of interconnectivity, and there is no separation or disjunction among cognition, bodily experience, and real-life theories. These experiences inform the art-making as practice. In the ultimacy of making through the lens of Indigenous knowledge, art-making as a product is encoded, and the process of making is transmitted through our senses. 


\section{Indigenous creative ways of knowing-a standpoint of sensorial meaning}

In all societies, culture influences art-making, as culture is integral to knowledge. Art, as a process, as noted above, is explicit and implicit in its presentation of multiple unfolding worldviews. I have already alluded to how specialized Indigenous knowing surrounds information bound in a long history. This form of interactive embodied knowing is what we have always called, and more recently heard, a country. The essential term country needs to be appreciated, and it must be realized how this refers to much more than a space or contained region (land) while still being a "geographical" location of ancestral connection. Country is where the earth, water, and the sky coalesce, and most importantly, country is imbued with expressive narratives from creational and pre-creational periods. Country is entwined within laws, social structures, and behaviors where every facet of landform, fauna, and flora is known to be alive and deeply respected. There is also the notion that Country, is a living thing, and this is most often when we hear the word. The cosmology of a living country not only informs the practices of art-making but can be seen to be the driving life force that makes the art. Being on country, the art-making is in response to the country as a living realm. This is quite anathematic to many Western ways of knowing, but there are exceptions of artists going on to land and replicating the images therein the art. What is unique to the world of Indigenous knowledge, as discussed here, is the cosmological dialogue that occurs.

With over 350 documented and different countries (nations) in Australia, each nation has its unique interpretation of ritualized practices and processes, particularly in art-making. Knowing is, therefore, based on historical experiences that continue to be adaptive, cumulative, and holistic in how we interact with the world. Indigenous knowledge is localized, culturally specific, and reflects a community's social values (Janke, 2003). Beyond the social values, the connection across these 350 countriesthe unifying factor is how the nation listens to and responds to the land-sky, sea, fauna, flora, and earth. Each country and the nation that looks to the country listens and responds in and through art-making (Janke, 2003).

Returning to the body of each of us, the sense of how our Indigenous knowledge captures the meaning given to us is now worthy of examination. Indigenous knowledge involving creative practices requires processes that capture the multisensorial nature of lived and felt experiences that promote self-reflection. This is because art-making can and must evoke emotions. Therefore, ways of knowing involve complex processes of seeing, being, doing, and feeling, which are often illustrated through a seemingly simplistic image or form. These Indigenous systems of knowing include and give precedence to embodied rituals, ceremonial spiritualism, and an inherent connection to the land (country). As noted earlier, the land speaks through these ritualized practices and transmits visual stories that serve us and are made visible to enrich knowledgesharing. The art-making form and image become a substantial direct and indirect exchange for making meaning. Spiritualism, along with cognition, bodily experience, and real-life theories, is infiltrated via bodily awareness and becomes known. This way 
of making meaning is central to understanding our lives. There is no opportunity to deny this reality for Indigenous people. The inherent connection of the land lies at the heart of intellectual sovereignty.

Art-making offers unique ways to build bridges between other cultures and thus enrich possibilities for genuine knowledge exchange (Rathwell \& Armitage, 2016). Although Indigenous art-making has reached global attention, spiritual and cultural esthetic knowledge remains on the parameters of Australia's dominant cultural ideologies (Folley, 2019), which are Western and, more often, white in their privileging of art. The dominant discourse is predominantly noted through language, which is constructed and patriarchal in nature. There are limitations in knowing through the written word and the spoken word. Any communication system that is too heavily based on language and number is limited. There is a sense of inadequacy when we need to express anything or everything we feel and sense. Therefore, art-making and viewing are often used in bridging the gap of words in both Indigenous and non-Indigenous ways of sensing. This paper contends that the arts allow us to say what literal language can never say.

The positivist paradigm and the cognitive mind-thought has become favored in Western societies; logos or word is privileged. In many Western worlds, emotion and somatic experiences (Damasio, 2009), along with creative thinking, are embedded in conceptual, analytical, and rigid bounded forms. There is limited attention paid to the function and perspective that value the immersion oneself within free-flow activities. Hence, through a Western point of view, there has been an unrecognized loss of multisensory immersion in the goal of processes in art-making. This paper brings these immersive multisensory experiences on country back to the readership. Western conceptions also generally have lost faith in the trustworthy source of selfknowledge and are now, more than ever, heavily influenced by social media and social technologies where choice-making is more limited and algorithm-driven. The omission of an internally felt and intensely lived experiences denies the vital part of everyday life, which is the very fabric of creative expression (see Figure 1). The loss of reliance on one's self-felt knowledge and experiences not only interrupts our deep connection with our senses and country but also threatens our psychological well-being as a therapeutic naturalizing activity (McKenna, 2015). The act of art-making is live-giving (physis) in all circumstances where we attend to our interiority. Physis here could mean a genesis (birthing) as opposed to death (Thanatos). Our collective conscious is linked with the order and strength of the land, which is unique to the art-making experience. This is especially true and significant for the Indigenous communities. The ground (country) brings us life.

\section{Sensory language in creative-making processes}

The way the senses are used in language within culture reveals much about a culture's sensory knowledge and embodied practices. Indigenous language differs from Western societies in that it is not restricted to just written interpretation but is constructed on an internal dialogue based on social and cultural norms. We must recognize that there is no language within any Australian Indigenous nation translating to the term "art." The 


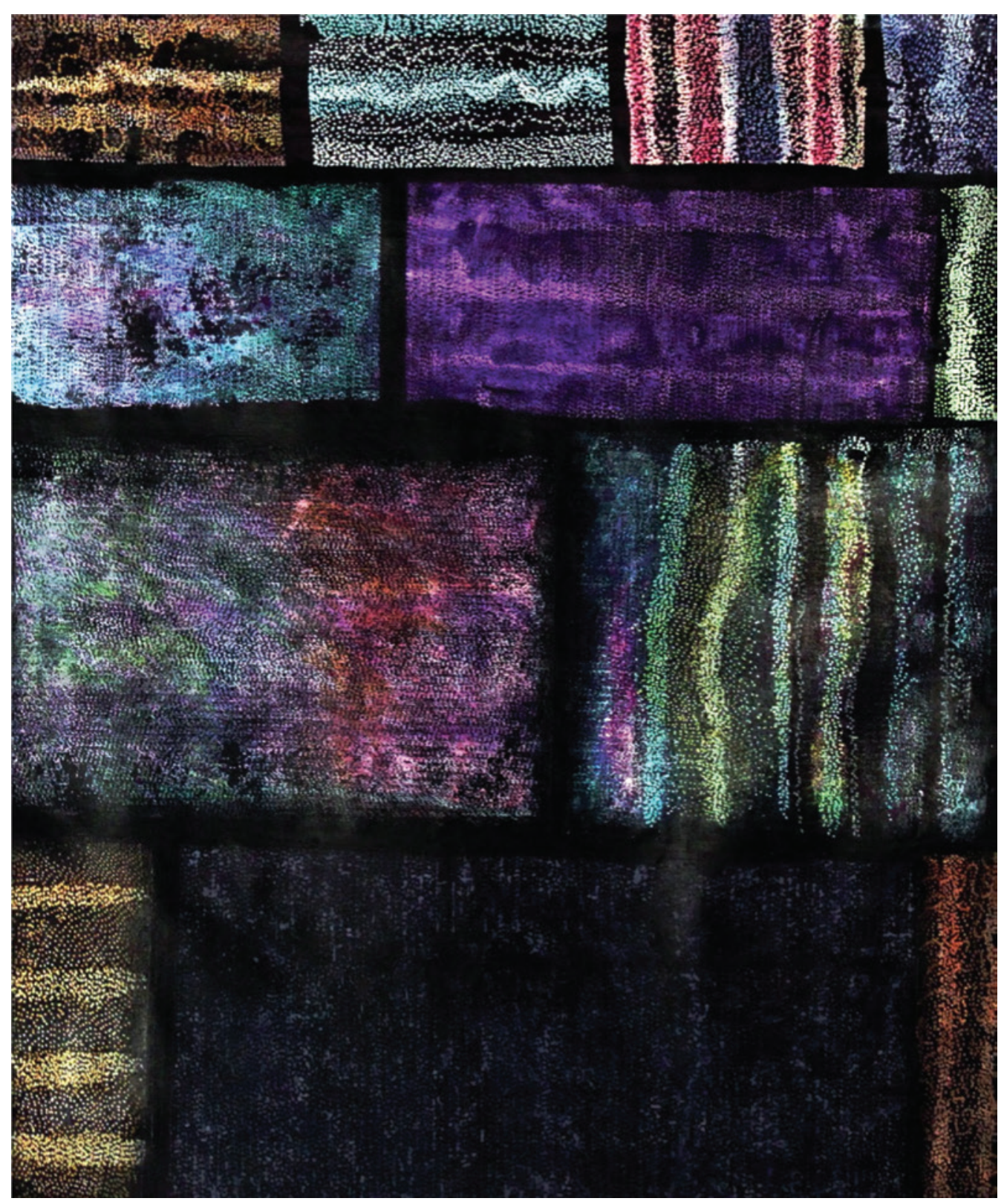

FIGURE 1 | Liz Cameron (Belanjee), Country-The Fabric of Being, acrylic and inks on canvas, $914 \times 457 \mathrm{~mm}$.

West has used the original word art to mean conveying cultural, intellectual; visual concepts are centered on knowledge and often without attention to an esthetic.

Within the Indigenous knowledge system, the actual process of making ("bangawarra") is through the engagement of the cultural human-nature connectedness 
that is guided by our human senses. Visual language, as bangawarra, is centered around cultural communication where symbols express more than words. The essential nature of moving beyond words is the core of bangawarra. A narrative form of "embodied thinking" (Levine, 1997, p. 41) would perhaps be more acceptable, as the embodiment is interpreted as how the body is an interactive process in cultural acquisition developed through the senses. But in defining Indigenous sensory knowledge systems, we are challenged in interpreting as verbs are more accurate than the use of nouns. For example, the noun sight is interpreted very differently from the verb seeing. Sight reflects one action, whereas seeing involves more profoundly observing. This is noted in various cultures across the globe, especially Javanese, which acknowledges having notions rasa or felt senses through a structured language discourse with verbs such as seeing, hearing, talking, smelling, and feeling (Geurts, 2003). Cultural language also influences how we define and make meaning of the human senses within creative processes and how we value our senses (Classen, 1999). This is demonstrated in how Eastern and Western cultures perceive our senses. Western customs, for instance, categorizes five senses (Dundes, 2007) within a hierarchical order, with sight as the "noblest" of the senses and touch classified as the "lowest" (Howes, 2006). Western culture also rank and label the proximal senses (touch, taste, and smell) as inferior (Holmes \& Spence, 2004), with the sense of sight considered the dominant mode for the progress of science and "object-centered thinking" (Pacey, 1999, pp. 39-57). From an Indigenous standpoint, this creates an imbalance of the senses, as relying merely on sight limits our full capacity to obtain an immersive bodily experience.

\section{The seven human senses of creativity in making}

Indigenous theories of the human senses consist of the external senses, which include seeing (vision), hearing (audition), tasting (gustation), smelling (olfaction), and touching (somatosensorial). The internal senses comprise of intuitive being ("oolgna") and imaginative knowing ("ngara"). While there is a loss within English translation, oolgna is interpreted as felt gut sensations - a natural bodily alertness that generates deep, emotionally felt insight. Ngara refers to the imaginary, an ability to observe through a sense of curiosity that is deeply grounded within memory and dreams. These seven senses combined are perceived as guides of the emotional unconscious and are consciously felt vibrations that perpetrate cognitive thinking. Hence, it is not the mind that drives creativity in practice but the deep connection we have with our body and the world around us.

\section{The external senses of seeing, hearing, tasting, smelling, and touching in making}

The way we see things is affected by what we know or what we believe (Berger, 1990). The external senses of Indigenous knowledge are noted as a multi-unified combination, as each sense is interrelated to the other rather than being separate identities. Our senses provide a deep awareness of the past, present, and offer future guidance when we are 
truly connected. As a self-reflective process, these senses provide us with insight, as "from feelings comes insight; from insight comes knowledge." Insight cannot be achieved through logical mind-thought but is transmitted through the act of doing.

\section{Ways of seeing}

Seeing surrounds observations that are influenced by our experiences, actions, and responses through sensory stimuli (Abrams, Klinger, \& Greenwald, 2002). Seeing a tree includes seeing its shape, form, and stance, touching its structure, tasting its fruits, smelling its unique scent, hearing its natural rhythmical breathing, intuitively connecting with its spiritual presence, and imagining its vibrational breaths. Deeply seeing allows the artist to view the world through shapes, colors, and objects they may have previously overlooked. By involving a more complete sensorial ontology in the studying shapes and objects, we witness new dimensions and imagine other possibilities. Seeing color can increase both the clarity and the affective impact in artmaking, but when we interpret color as a sensation, we are instantly transformed from conventional thinking into a more subjective viewpoint that enlightens our experience.

Many Indigenous artists use bright colors in full spectra to evoke, convey, and enhance the viewer's experience, as vivid hues represent social and spiritual sentiments that transform the initial subject matter. The use of geometric shapes cultivates sound (music) through a psychedelic illusion of space within size, shape, and positioning. The use of abstract repetitive patterns and the deployment of an unrestricted broad spectrum of colors of dots and lines create not only generates movement or depth but also an interplay of optical effects that infiltrates our senses into being reactive. For example, Indigenous artist Natalie Bateman utilizes dots and geometric shapes that represent land markings such as hills, rivers, coastlines, and the cosmos. Her ideas come from everyday living, and the stories passed down from her Elders. Bateman uses repetitions of color to create unity and harmony that leads the viewer's eye from one shape to another. Another Indigenous artist Kudditji Kngwarreye uses sophisticated large blocks of subtle contrasting colors, merged with sweeping brushstrokes that are reminiscent of his country, by applying textured geometric square and rectangular shapes that reflect subjective experiences of form and content. Kudditji infuses his works by singing the stories of his country that echo the Australian desert into an abstract interplay of makings and language.

\section{Ways of smelling}

Smelling offers the artist a way of connecting with the environment (country) with varying odors evoking and triggering memory across times and spaces. Scent affects us on both physical, psychological, and social levels. Smelling also influences our emotional states and reactionary behaviors through associations of pleasant or pungent odors (Chen \& Haviland-Jones, 2000). Pleasant smells bring feelings of calmness, which accentuates the artist's sensual experiences. Using scent within art practices also increases self-reflection (Barss, 2000) to generate more powerful responses in our perceptions of flavors, as smelling gives an artform flavor. For instance, artist Sissel 
Tolaas works with fragrance to explore the importance of olfaction within the human culture. Her multidisciplinary approach investigates olfactory encounters by inviting viewers to smell the aroma and connect with their memories. Maki Ueda also explores olfaction concerning space and movement with smelling sparking the imagination.

Traditionally, Indigenous artists combined various natural ochre pigments with plant materials to create strong odors to empathize with the human-nature connection. Indigenous artist Clinton Nain offers another expressive reaction to smelling by using reactive materials such as bitumen paint and domestic household bleach as a medium to express truthfulness around aspects of Indigenous life. Nain's works create intensive sensory experiences by using the strong, active components of bitumen as a ground surface and applying acrylics over the top to illustrate disorder and chaos. The pungent smell of asphalt, along with the peeling and cracked acrylic surface, stimulates our senses into an emotional realism of toxicity associated with pain and disgust.

\section{Ways of hearing}

Hearing allows us to listen to the natural vibrations of our environment and plays an integral part in Indigenous art-making. Capturing sounds through rhythmical lines, circular movements, and vivid hues facilitate our cultural embodiment. Applying rhythmical symbolic patterning highlights the immersive power of the sensory connection in synchronizing with auditory responses. Synchronizing in art-making liberates expression between sound and space and evokes a transcending experience of psychological effect (Husain, Thompson, \& Schellenberg, 2002). Artist John Cage, for example, pushes our understanding of sound through his development of musical maps by combining art-making with music that blends familiar elements of notations with unconventional objects such as squiggles, wavy lines, and illuminating colors. Sound is uniquely captured from many Indigenous artists who construct sensory, auditory mosaics designed to invite listeners to hear art-making speak (see Figure 2. This internal dialogue offers an organic element of the rhythmical structure. Indigenous artists like Rodney Jungala King embed their traditional language and songs into visual narratives to illustrate their country's creational stories. King constructs geographical maps that are interwoven with ritualized cultural landscapes. Many other Indigenous artists use natural wood materials to make musical instruments such as the didgeridoo (yidaki), clapstick, and bullroarers. World-renowned yidaki craftsman Djalu' Gurruwiwi, expresses the tool as an extension of himself as a way of highlighting the sacredness surrounding the human-nature connection. These instruments are handcrafted with intricate designs that represent cultural values by using symbols related to their own country.

\section{Ways of touching}

Touching relates to the reactive sensory transmitters that provide information on the internal and external environments. Tactile explorations create an extension in knowing through the felt vibrations of the natural pulsations of different frequencies where our bodies unite in synchronization. For example, our finger's functional role is to perceive surface textures, feel pressure changes in temperature, and various other 


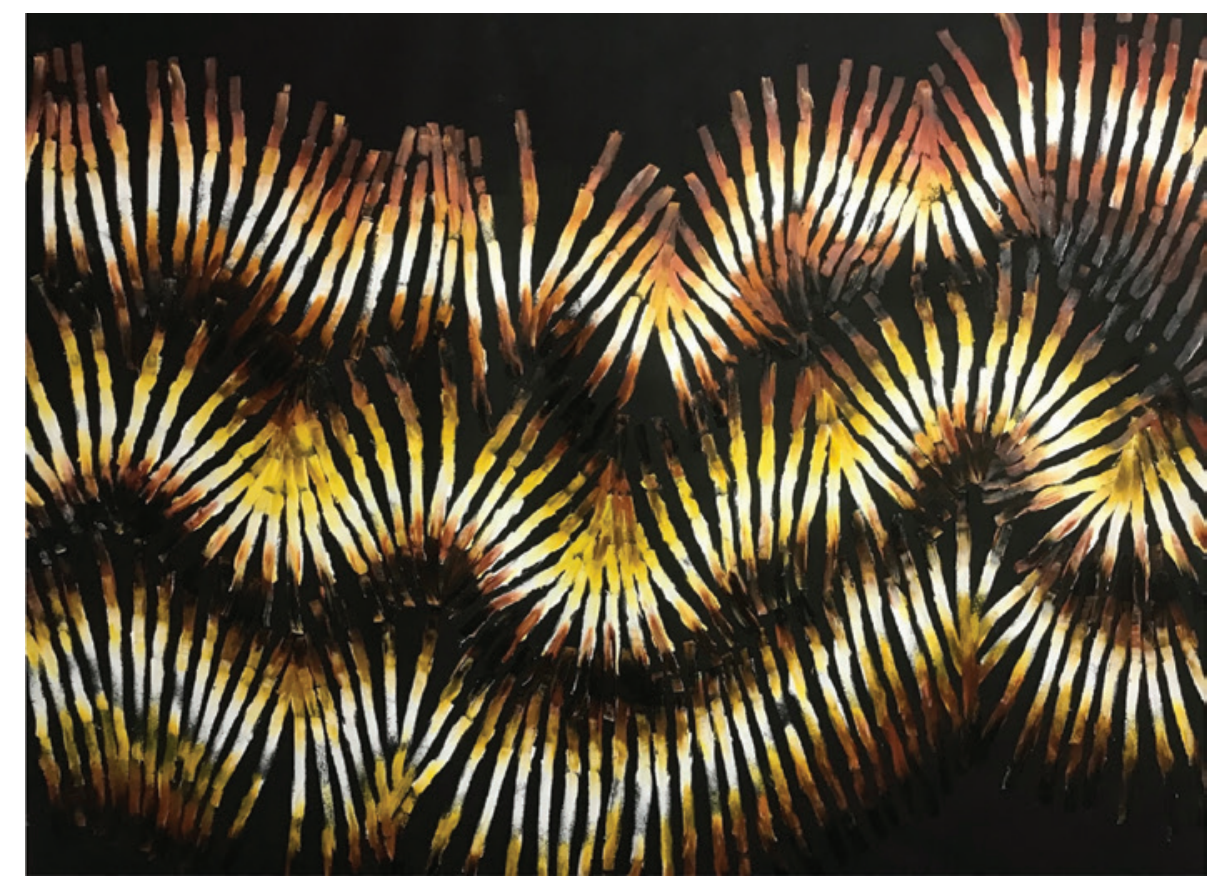

FIGURE 2 | Liz Cameron (Belanjee), Hearing Country Speak, Sunburnt Melodies, oils on canvas, $2133 \times 1828 \mathrm{~mm}$.

fluctuations. These tactile interactions allow the artist to gain further information through bodily-kinesthetic intelligence, which not only offers genuine authenticity but a receptive conduit of free-flow abilities (Csikszentmihalyi, 1997). Through physical contact, we can feel the contours, tautness, and rigidity of an artwork, which allows for further contemplations of judgment concerning shape, style, texture, and substance of form. The tactile experience of touching within creative making is illustrated by Indigenous weaver Anawari Inpiti Mitchell who works with experimental sculptural forms. Mitchell creates images of animals inspired by her local environment using fiber art that represents a medium of ceremonial and cultural material. Thompson Yulidjirri also uses the sense of touching by making traditional fish traps that hold great spiritual significance associated with replenishing and renewal. Yulidjirri dyeing processes incorporate root fibers and specific plants painted with ochre and animal fat to push the limits of these materials. His work is both tactic and responsive to cultural knowledge.

\section{Ways of tasting}

Tasting contributes to self-perception and self-analysis, as flavor allows the artist selfanalysis through memory recall. Artists have portrayed food in various creative ways for centuries, yet the ones that capture most attention involve depictions where the viewer feels they can taste the object. For many Indigenous artists capturing taste is an essential 
part of cultural knowledge, as they act as visual guides or maps of where food sources are located. The use of aerial mapping in Indigenous art-making techniques often represents specific foods to convey essential information. The use of natural pigments and ochres is traditionally mixed with natural gum resins and animal-derived oils/fats from binding, retaining and preserving the color. Many of these products are edible to highlight the value of our natural resources. Indigenous artist Polly Ngale, whose subject matter of fruit is drawn from acute observation (deep seeing) as a source of knowledge relating to country. Josie Petrick Kemarre illustrates the bush yam, native to her country, by showing the seasonal cycles of bush berries as an essential part of knowing.

\section{The internal senses}

The role of intuition in creativity should not be overlooked, as it is not only a core component of creative cognition but enables the artist to apply originality through deliberative reasoning (Hodgkinson, Sadler-Smith, Burke, Claxton, \& Sparrow, 2009). As a form of knowledge, intuition appears without apparent deliberation. Often referred to as "gut feeling," this intuitive sense influences decision-making and subsequent actions in daily life (Kahneman, 2011) through felt vibrations that originate in the gut area. This internally felt sense is often reactive in times of stress or fear and acts as a spreading process that circulates throughout the body. Many cultures describe intuition as the knowledge center located in the stomach (gut) region and a spiritual engagement through listening to, trusting in, and acting upon inner guidance (Aurobindo 2006). Buddhism, for example, describes the intuitive mind as an active feeling element in our body (Henden, 2004): the Japanese uses the term "hara," which translates to "sea of energy," and Chinese culture uses the term "dantian" to express gut reactivities. Gershon (1998) offers similar references to the stomach area as the enteric or second brain independent of the mind-brain, in its own autonomous reflexes. In a recent Australian study on interactive human-centered approaches in art-making by Loke and Robertson (2013), they explored the connections between the method of bodily awareness in kinesthetic skills and how audiences experience artworks. Examining interactive art and performance, the team investigated navel radiation, a movement initiated in the central stomach area (Berland, 2003 , p. 3). Navel radiation is based on the idea that movement rippling out from the navel to our body is a body-mind somatic experience in esthetic practices. Findings from the study indicate that navel radiation is central to exploring our surroundings. This study also suggests that the mind is expressed through the body.

From an Indigenous standpoint, oolgna is our intuitive center of thinking, doing, and being. Intuitive knowing (oolgna) is considered an internalized, enduring emotional signal that is core to thinking (Cameron, 2015). It is an intelligence center located in the stomach region behind the umbilical cord. In visual language, it is illustrated through the symbol of the spiral that projects out through an anticlockwise motion. The anticlockwise movement corresponds with shifts of wave movement in the southeast area of Australia. It is representational of the throwing out of energy (knowledge) from within. Recent research (Ranasinghe, Short, \& Symonds, 2004) affirms that wave directions in the southern hemisphere have an anticlockwise movement along with the sun and its shadows, which has a similar trend. 


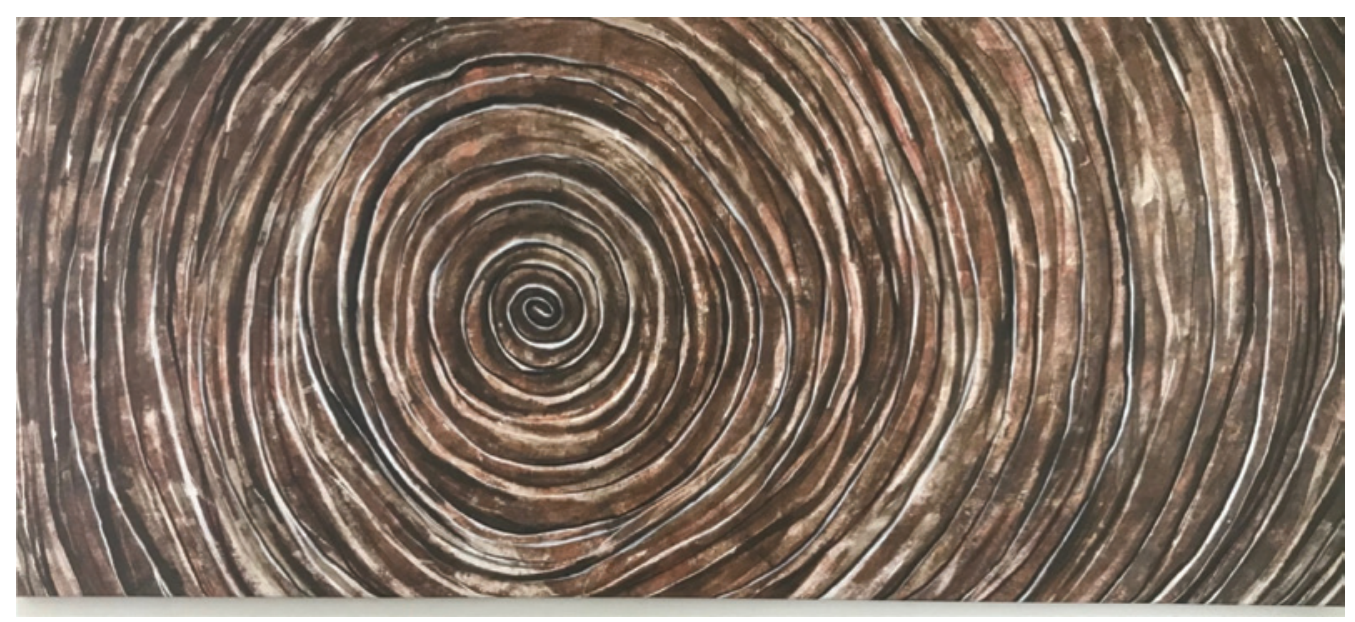

FIGURE 3 | Liz Cameron (Belanjee). Oolgna, The Relationship with Self and the Natural World, acrylic on canvas, $2438 \times 1299 \mathrm{~mm}$.

Resynchronizing with oolgna requires a meditative state to reconnect with our senses and see beyond existing embedded thoughts. By aligning the stomach area to the natural rhythmical sounds of the environment, we feel and hear uniformity, which builds our relationship with the natural world (see Figure 3). Aligning our bodies with the natural environmental patterns and rhythms forges our conceptual thinking through acoustic signals of melody, rhythm, harmony, and texture.

Intuitive knowing plays an essential role in analyzing and retrieving information within creative practice. In viewing Indigenous artist Ildiko Kovacs's work, we can connect our body to the natural rhythms of connection. Kovac uses intuitive knowing by applying repetitive patterning as a tool to detect and interact with its message. Kovac experiments with paint-rollers that open a new process of mark-making by using large gestures of rhythmical forms. Her work expresses the internal rhythms and emotions spontaneously. Kovac applies multiple layering processes by building up and removing paint to inject movement and energetic expression. There is no pre-drawing or planning, as her process involves felt responses in manipulating the canvas. Kovac maps the movement of the landscape, responding intuitively to balance, surface tension, and the interplay of color. Renowned for her highly distinctive pandanus and paperbark fiber sculptures, Indigenous artist Lena Yarinkura also uses intuitive skills when applying ochre pigments into the textured weave of pandanus fibers to depict the water spirits. Her sculptures carry deep spiritual meaning through linear techniques that convey the essence of knowing.

\section{Ways of imagining}

Imagination is the process of feeling and forming mental images or concepts achieved through dreams or deep contemplation. It is an apparatus through which an artist can make sense of the world. The imaginative process is associated with social 
communication and is core to cultural construction (Säljö \& Rystedt, 2008). Ways of imagining are exploring, experimenting, and being able to extend our usual boundaries of intellectual concepts by being flexible and open as to what is brought to mind. Most notably, art-making "play[s] to the imagination" (Gadsden, 2008, p. 47) as a way to reshape and revise our own "hidden and subjective" lives (Abbs, 2003, p. 13). As a human activity, imagining induces the other senses to channel the artist's thinking. In other words, to create something new, it must beforehand be imagined or envisioned. Imagining concerns original thinking, as we can envisage how things might have been or could be. Connecting with imaginative feelings and thoughts facilitates new ideas by building a sense of curiosity about the unpredictable and the unpredicted. Imaginative knowing is, therefore, a boundlessness release "in looking at the world with a fresh approach to what we take for granted" (Monk, 1990). As we awaken our imaginative senses, we can disclose the ordinarily unheard and unexpected to allow for a free flow of emotional input. Indigenous artists often express that their art-making is a spiritually guided process that transforms their process in the making and hence goes beyond mere personal experiences. By applying imaginative methods, Indigenous artist Jan Billycan mixes colors repeatedly in her line-works until they achieve a strong density that reflects the uniqueness and individuality of her country. As a traditional healer, Billycan transforms art-making by utilizing strong metaphoric references to human organs in her landscapes. Her paintings depict imagery of a living and breathing environment by using multilayering patterns and grainy textures that portray a psychological effect in conveying emotional energy through an imaginative process.

\section{Conclusion}

As multisensory beings, our bodies can push our artistic encounters and challenge our past ways of thinking and doing. By connecting with our multisensory experiences, we can respond to stimuli on an automatic or preconscious level. This rich interplay offers artists an immersive experience and a more meaningful transformational process in art-making. As multisensory artists, we can instinctively feel the coldness of ochre clay, smell the rich odor of oils, touch the smoothness of wooden tools, and dance the natural rhythms of our environments on an unparalleled level. When we start to view ourselves as multisensory beings, the intuitive and imaginative processes become a more automatic response that enables us to be more expressive. Multisensory making allows the artist to think beyond conventional making, which can have a more profound influence on the viewer's experiences. By communicating our emotions, we enrich our experiences, and communication transfers broaden our interactions with self and the environment.

\section{Acknowledgement}

There is no funding related to this manuscript. 


\section{About the Author}

Liz Cameron is a professor of Indigenous knowledges at Deakin University. She is affiliated with the Dhaurg Nation, located northwest of the Sydney region in New South Wales, Australia. Her research focuses on Indigenous knowledges within a creative framework as a process to express cultural content.

\section{References}

Aurobindo, Sri (2006). Autobiographical Notes and Other Writings of Historical Interest. The Complete Works of Sri Aurobindo, Vol. 36. Pondicherry: Sri Aurobindo Ashram Publication Department.

Abbs, P. (2003). Against the flow: Education, the arts and postmodern culture. Routledge Falmer.

Abrams, R. L., Klinger, M. R., \& Greenwald, A. G. (2002). Subliminal words activate semantic categories (not automated motor responses). Psychonomic Bulletin \& Review, 9, 104-106.

Barss, Andrew (2000) Minimalism and asymmetric wh-interpretation. In Roger Martin, David Michaels, and Juan Uriagereka (eds.), Step by Step: Essays on Minimalism in Honor of Howard Lasnik. pp. 31-52. Cambridge, MA: MIT Press.

Berger, J. (1990). Ways of seeing. Penguin.

Berland, E. (2003). Body-mind centering as somatic education for students and practitioners of voice. http://www.erikaberland.com/art_unpub.html.

Cameron, L. (2015). Is it art or knowledge? Deconstructing Australian Aboriginal creative making. International Arts, 4, 68-74.

Chen, D., \& Haviland-Jones, J. (2000). Human olfactory communication of emotion. Perceptual and Motor Skills, 91, 771-781.

Classen, C. (1999). Other ways to wisdom: Learning through the senses across cultures. International Review of Education, 45, 269-280.

Csikszentmihalyi, M. (1997). Finding flow: The psychology of engagement with everyday life. Basic Books.

Damasio, A. (2009). Self comes to mind. Vintage.

Dundes, A. (2007). Meaning of folklore: The analytical essays of Alan Dundes. University Press of Colorado.

Folley, D. (2019). Indigenous methodology: Is it invented or is it legitimate? Journal of Australian Indigenous Issues, 21, 20-38.

Gadsden, V. (2008). The arts and education: Knowledge generation, pedagogy and the discourse of learning. Review of Research in Education (32), 29-61.

Gershon, M. (1998). The second brain. Harper Collins.

Geurts, K. (2003). Culture and the senses: Bodily ways of knowing in an African community. University of California Press.

Henden, G. (2004). Intuition and its role in strategic thinking. Norwegian School of Management.

Hodgkinson, G. P., Sadler-Smith, E., Burke, L. A., Claxton, G., \& Sparrow, P. R. (2009). Intuition in organizations: Implications for strategic management. Long Range Planning, 42, $277-297$.

Holmes, N. P., \& Spence, C. (2004). The body schema and the multisensory representation(s) of peripersonal space. Cognitive Processing, 5, 94-105.

Howes, D. (2006). Charting the sensorial revolution. The Senses and Society, 1, 113-128.

Husain, G., Thompson, W. F., \& Schellenberg, E. G. (2002). Effects of musical tempo and mode on arousal, mood, and spatial abilities. Music Perception, 20, 151-171.

Janke, T. (2003). Minding cultures: Case studies on intellectual property and traditional cultural expressions. World Intellectual Property Organization.

Levine, S. (1997). The language of psychology and speech of the soul. Jessica Kingsley.

Loke, L., \& Robertson, T. (2013). Moving and making strange: An embodied approach to movement-based interaction design. ACM Transactions on Computer-Human Interaction, 20, article 7.

McKenna, T. (2015). The business of validity, reliability and authentic need. The Praxis of English Language Teaching and Learning (PELT), 45-60. 
Monk, M. (1990). Some thoughts about art, America and jumping off the cliff. http://gos.sbc.edu/m/monk1. html.

Pacey, A. (1999). Meaning in technology. MIT Press.

Pascual-Leone, A., Amedi, A., Fregni, F., \& Merabet, L. B. (2005). The plastic human brain cortex. Annual Review of Neuroscience, 28, 377-401.

Ranasinghe, R., M. R., Short A., \& Symonds G. (2004). The Southern Oscillation Index, wave climate, and reach rotation. Geology, 204, 273-287.

Rathwell, K. J., \& Armitage, D. (2016). Art and artistic processes bridge knowledge systems about socialecological change: An empirical examination with Inuit artists from Nunavut, Canada. Ecology and Society, 21, 21.

Säljö, R. E., \& Rystedt, H. E. (2008). Kunskapochmänniskansredskap: teknikochlärande. Studentlitteratur. 